\title{
Anestesi Spinal Dosis Rendah Untuk Pasien Operasi Sesar dengan Stenosis Mitral Berat
}

\section{Low Dose Spinal Anesthesia For Caessarian Section Delivery in Patient with Severe Mitral Stenosis}

\author{
Ruddi Hartono ${ }^{\bowtie}$, Isngadi, Dewi Puspitorini Husodo \\ Departemen Anestesiologi dan Terapi Intensif, Fakultas Kedokteran, Universitas Brawijaya/ \\ RSU dr. Saiful Anwar, Malang, Indonesia \\ ${ }^{\square}$ Korespondensi: $\underline{\text { Hartonoruddi@gmail.com }}$
}

\begin{abstract}
Background: Approximately 25\% of patients with mitral stenosis become symptomatic for the first time during pregnancy. It is because of increasing maternal blood volume and heart rate. Some literature mentioned that spinal anesthesia is contraindicated for the patient with mitral stenosis undergo operation due to the risk of hypotension and tachycardia.

Case: A 24-years old primigravida in 32-34 weeks of gestation with severe mitral stenosis, mild mitral regurgitation, moderate tricuspid regurgitation, moderate pulmonal regurgitation. Ejection Fraction (EF) was 62\%, pulmonary hypertension with pulmonary artery systolic pressure (PASP) $65 \mathrm{mmHg}$, heart failure stage C Functional Class III. Caessarian section was performed under low dose spinal anesthesia using $5 \mathrm{mg}$ of bupivacaine and $50 \mathrm{mcg}$ of fentanyl as adjuvant. Complete neuraxial block was achieved in 5 minutes. The haemodynamic was stable during the operation. There is no evidence of acute heart failure and worsen of hemodynamic status in postoperative periods. The patient discharge safely from the hospital.

Discussion: The main principles of anesthesia management is to prevent tachycardia, maintain sinus rhytm and aggressively treat new atrial fibrillation using pharmacologic drugs or cardioversion. Systemic vascular resistance (SVR) is kept normal especially in patient with unstable hemodynamic because the decrease of SVR can induce tachycardia. Another strategy are maintain normovolemia, prevent hypoxia, hipercarbia and pain.

Conclusion: Low dose spinal anesthesia using $5 \mathrm{mg}$ of bupivacaine heavy 0,5\% and adjuvant fentanyl can be safely used for caessarean section delivery in severe mitral stenosis patient because of the fast onset, adequacy level, duration of the block, haemodynamic stability and good fetal outcome.
\end{abstract}

Keywords: caesarean section; low dose; mitral stenosis; neuraxial block; spinal anesthesia 


\begin{abstract}
ABSTRAK
Latar belakang: Stenosis mitral banyak ditemukan pada kehamilan, dimana sekitar 25\% pasien akan mengalami gejala pada kehamilan pertama. Hal ini disebabkan karena adanya peningkatan volume darah dan nadi. Beberapa literatur menyebutkan bahwa anestesi spinal dikontraindikasikan pada pasien yang akan menjalani operasi dengan kelainan stenosis mitral karena risiko terjadinya hipotensi dan takikardia.

Kasus: Perempuan 24 tahun primigravida, usia kehamilan 32-34 minggu dengan stenosis mitral berat, regurgitasi mitral ringan, regurgitasi trikuspid sedang, regurgitasi pulmonal sedang (EF 62\%), hipertensi pulmonal sedang (PASP $65 \mathrm{mmHg}$ ), gagal jantung stadium $\mathrm{C}$ kelas fungsional III menjalani operasi sesar dengan low dose anestesi spinal menggunakan $5 \mathrm{mg}$ bupivacaine heavy $0,5 \%$ dan $50 \mathrm{mcg}$ fentanyl volume total $2 \mathrm{ml}$. Blok spinal dicapai dalam waktu 5 menit. Hemodinamik stabil selama perioperatif. Tidak terjadi gagal jantung akut maupun perburukan hemodinamik pascaoperasi.

Pembahasan: Prinsip pembiusan pasien dengan mitral stenosis adalah menghindari takikardia, menjaga kondisi sinus rhytm dan secara agresif mengatasi atrial fibrilasi baik farmakologis maupun dengan kardioversi terutama pada pasien dengan hemodinamik tidak stabil, menghindari penurunan SVR yang akan meningkatkan denyut jantung sehingga memperberat kerja jantung, menghindari hipovolemi, kelebihan cairan, dan faktor yang meningkatkan tekanan arteri pulmonal seperti hipoksia dan hiperkarbia maupun nyeri.
\end{abstract}

Kesimpulan: anestesi spinal dosis rendah menggunakan $5 \mathrm{mg}$ bupivakain dan ajuvan fentanyl dapat digunakan pada operasi operasi sesar pada pasien dengan stenosis mitral berat karena awitan yang cepat, level blok yang adekuat, durasi blok hemodinamik yang stabil dan bayi yang lahir dengan kondisi yang baik.

Kata kunci: anestesi spinal; blok neuraksial; dosis rendah; operasi sesar; stenosis mitral

\section{PENDAHULUAN}

Kelainan jantung pada kehamilan masih menjadi faktor utama non obstetrik penyebab morbiditas dan mortalitas pada ibu hamil. Salah satu yang masih menjadi masalah diantara kelainan jantung pada kehamilan ini adalah kelainan katup berupa stenosis mital. Kejadian stenosis mitral semakin meningkat di kawasan Asia seiring dengan peningkatan penyakit demam reumatik. Carapentis memperkirakan 15,6 juta penduduk dunia menderita penyakit jantung reumatik, dengan kasus baru demam reumatik akut 470 ribu penduduk dan 233 ribu orang meninggal akibat demam reumatik akut dan penyakit jantung reumatik. ${ }^{1,2,3}$
Stenosis mitral sendiri merupakan kelainan katup yang paling umum terjadi berkaitan dengan penyakit demam reumatik. Kelainan patologis stenosis mitral pada kehamilan berhubungan dengan adanya edema paru akut dan penyakit katup aorta. Gejala yang timbul tergantung beratnya ringannya stenosis mitral, meliputi fatigue dan dyspneu pada awalnya, kemudian dapat menyebabkan paroxysmal nocturnal dyspneu, orthopnea dan nafas pendek pada saat istirahat. Angka mortalitas sendiri sekitar $1 \%$ pada stenosis mitral ringan dan $5-15 \%$ pada stenosis mitral berat. Hingga saat ini, tindakan operasi sesar pada pasien hamil dengan kelainan stenosis mitral masih menjadi tantangan 
bagi ahli anestesi dalam memberikan tatalaksana anestesi yang sesuai. ${ }^{1}$

Penyebab tersering dari stenosis mitral adalah endokarditis reumatik, akibat reaksi yang progresif dari demam reumatik oleh infeksi streptococcus. Diperkirakan $90 \%$ stenosis mitral didasarkan atas penyakit jantung reumatik. Penyebab lainnya walaupun jarang yaitu stenosis mitral kongenital, vegetasi dari systemic lupus eritematosus (SLE), deposit amiloid, mucopolysaccharidosis, rheumatoid arthritis (RA), Wipple's disease, Fabry disease, akibat obat fenfluramin/ phentermin, serta kalsifikasi annulus maupun daun katup pada usia lanjut akibat proses degeneratif.,

Pada keadaan normal katup mitral mempunyai ukuran 4-6 $\mathrm{cm}^{2}$, bila area orifisium katup berkurang sampai $2 \mathrm{~cm}^{2}$, maka diperlukan upaya aktif atrium kiri berupa peningkatan tekanan atrium kiri agar aliran transmitral yang normal dapat terjadi. Ini terjadi akibat adanya fibrosis dan fusi komisura katup mitral pada waktu fase penyembuhan demam reumatik. Stenosis mitral kritis terjadi bila pembukaan katup berkurang hingga menjadi $1 \mathrm{~cm}^{2}$. Pada tahap ini diperlukan suatu tekanan atrium kiri sebesar 25
mmHg untuk mempertah ankan cardiac output yang normal. Peningkatan tekanan atrium kiri akan meningkatkan tekanan pada vena pulmonalis dan kapiler, sehingga bermanifestasi sebagai exertional dyspneu. Seiring dengan perkembangan penyakit, peningkatan tekanan atrium kiri kronis. akan menyebabkan terjadinya hipertensi pulmonal, yang selanjutnya akan menyebabkan kenaikan tekanan dan volume akhir diastolik, regurgitasi trikuspid dan pulmonal sekunder dan seterusnya sebagai gagal jantung kanan dan kongesti sistemik. ${ }^{6}$

Hipertensi pulmonal merupakan komplikasi yang sering terjadi pada stenosis mitral. Pada awalnya hipertensi pulmonal terjadi secara pasif akibat kenaikan tekanan atrium kiri, terjadi perubahan pada vaskular paru berupa vasokonstriksi akibat endotelin atau perubahan anatomi yaitu remodelling akibat hipertrofi tunika media dan penebalan intima (reactive hypertension). ${ }^{6,7}$ Pelebaran progresif dari atrium kiri akan memicu dua komplikasi lanjut, yaitu pembentukan trombus mural yang terjadi pada sekitar $20 \%$ penderita, dan terjadinya atrial fibrilasi yang terjadi pada sekitar $40 \%$ penderita. $^{8}$

Tabel 1. Hubungan antara gradien dan luasnya area katup serta waktu pembukaan katup mitral

\begin{tabular}{llll}
\hline Derajat stenosis & A2-OS interval & Area & Gradien \\
\hline Ringan & $>110 \mathrm{msec}$ & $>1,5 \mathrm{~cm}^{2}$ & $<5$ \\
Sedang & $80-110 \mathrm{msec}$ & $>1 \mathrm{~cm}^{2}-1,5 \mathrm{~cm}^{2}$ & $5-10 \mathrm{mmHg}$ \\
Berat & $<80$ & $<1 \mathrm{~cm}^{2}$ & $>10 \mathrm{mmHg}$ \\
\hline
\end{tabular}


Tabel 2. Derajat mitral stenosis

\begin{tabular}{lcccc}
\hline Pengukuran & Normal & Ringan & Sedang & Berat \\
\hline Area katup mitral $\left(\mathrm{cm}^{2}\right)$ & $4.0-6.0$ & $1.5-2.5$ & $1.0-1.5$ & $<1.0$ \\
Rerata gradien tekanan $(\mathrm{mmHg})$ & $<2$ & $2-6$ & $6-12$ & $>12$ \\
Rerata tekanan arteri pulmonalis & $10-20$ & $<30$ & $30-50$ & $>50$ \\
\hline
\end{tabular}

Dengan bertambah sempitnya area mitral maka tekanan atrium kiri akan meningkat bersamaan dengan progresi keluhan. Apabila area mitral $<1 \mathrm{~cm}^{2}$ yang berupa stenosis mitral berat maka akan terjadi pembatasan dalam aktivitas. ${ }^{8-12}$

\section{Perubahan Fisiologis Kehamilan}

Kebutuhan janin yang sedang bertumbuh akan oksigen dan zat-zat makanan bertambah dalam berlangsungnya kehamilan, yang harus dipenuhi melalui darah ibu. Untuk itu banyaknya darah yang beredar bertambah, sehingga jantung harus bekerja lebih berat. Karena itu dalam kehamilan selalu terjadi perubahan dalam sistem kardiovaskular yang biasanya masih dalam batas fisiologis. Penyakit jantung akan menjadi lebih berat pada pasien yang hamil dan melahirkan, bahkan dapat terjadi dekompensasi jantung. ${ }^{5,7,10}$

Tabel 3. Perubahan kardiovaskular selama kehamilan

\begin{tabular}{ll}
\hline Parameter & Perubahan \\
\hline Cardiac output & $40-50 \%$ meningkat \\
Stroke volume & $30 \%$ meningkat \\
Heart rate & $15-25 \%$ meningkat \\
Intravascular volume & $45 \%$ meningkat \\
Systemic Vascular Resistance & $20 \%$ menurun \\
Tekanan Darah Sistolik & Minimal \\
Tekanan Darah Diastolik & $20 \%$ menurun pada tengah kehamilan \\
CVP & Tidak berubah \\
Konsumsi O2 & $30-40 \%$ meningkat \\
\hline
\end{tabular}

Tabel 4. Perubahan kardiovaskular selama persalinan

\begin{tabular}{lll}
\hline Parameter & Tahap Persalinan & Perubahan \\
\hline Cardiac Output & Fase laten & $10 \%$ meningkat \\
& Fase akif & $25 \%$ meningkat \\
& Fase Ekspulsif & $40 \%$ meningkat \\
Heart Rate & Immediate Post-partum & $75-80 \%$ meningkat \\
CVP & Semua tahap persalinan & Meningkat \\
\hline
\end{tabular}


Tabel 5. Perubahan kardiovaskular pasca persalinan

\begin{tabular}{lll}
\hline Parameter & Post-Partum & Persentase Perubahan \\
\hline Cardiac Output & Dalam 1 jam & $30 \%$ lebih diatas nilai pre-persalinan \\
& $24-48$ jam & Dibawah nilai pre-persalinan \\
& 2 minggu & $10 \%$ diatas nilai pre-kehamilan \\
& $12-24$ minggu & Nilai batas pre-kehamilan \\
Heart rate & Immediate & Menurun \\
& 2 minggu & Nilai pre-kehamilan \\
Stroke volume & 48 jam & Diatas nilai pre-persalinan \\
& 24 mingggu & $10 \%$ diatas nilai pre-persalinan \\
\hline
\end{tabular}

\section{Manifestasi Klinis}

Kebanyakan penderita stenosis mitral bebas keluhan dan biasanya keluhan utama berupa sesak napas dan dapat juga berupa fatigue. Pada stenosis mitral yang bermakna dapat mengalami sesak pada aktivitas sehari-hari, paroxysmal nocturnal dyspnea, orthopnea atau edema paru. Aritmia atrial berupa fibrilasi atrium juga merupakan kejadian yang sering terjadi pada stenosis mitral, yaitu $30-40 \%$. Sering terjadi pada usia yang lebih lanjut atau distensi atrium yang akan merubah sifat elektrofisiologi dari atrium kiri dan hal ini tidak berhubungan dengan derajat stenosis.

Manifestasi klinis dapat juga berupa komplikasi stenosis mitral seperti tromboemboli, infektif endokarditis atau simtomatis karena kompresi akibat besarnya atrium kiri seperti disfagia dan suara serak. Perlu diawasi saat-saat berbahaya bagi penderita penyakit jantung yang hamil yaitu: (1) antara minggu ke 12 dan 32. Terjadi perubahan hemodinamik, terutama minggu ke 28 dan 32, saat puncak perubahan dan kebutuhan jantung maksimum; (2) saat persalinan. Setiap kontraksi uterus meningkatkan jumlah darah ke dalam sirkulasi sistemik sebesar $15-20 \%$ dan ketika meneran pada partus kala dua, saat arus balik vena dihambat kembali ke jantung; (3) setelah melahirkan bayi dan plasenta. Hilangnya pengaruh obstruksi uterus yang hamil menyebabkan masuknya darah secara tiba-tiba dari ekstremitas bawah dan sirkulasi uteroplasenta ke sirkulasi sistemik; (4) antara 4-5 hari setelah persalinan. Terjadi penurunan resistensi perifer dan emboli pulmonal dari trombus iliofemoral. ${ }^{13,14}$

Gagal jantung biasanya terjadi perlahanlahan. Gejala dan tanda yang biasa ditemui adalah dyspnea dan orthopnea yang berat atau progresif, paroxysmal nocturnal dyspnea, sinkop pada kerja, nyeri dada, batuk kronis, hemoptisis, jari tabuh, sianosis, edema persisten pada ekstremitas, peningkatan vena jugularis, bunyi jantung I yang keras atau sulit didengar, split bunyi jantung II, ejection click, late systolic click, opening snap, friction rub, bising sistolik derajat III atau IV, bising diastolik, dan kardiomegali dengan heaving ventrikel kiri atau kanan yang difus. ${ }^{10,15,16}$

\section{Diagnosis}

Diagnosa mitral stenosis ditegakkan melalui pemeriksaan klinis dan penunjang. Gejala klinis utama adalah sesak saat beraktivitas, nyeri dada, palpitasi dan paroxysmal nocturnal dyspneu. Ditambah dengan pemeriksaan penunjang seperti rontgen, EKG dan ekokardiografi sebagai standar pada pemeriksaan kecurigaan adanya mitral 
stenosis. Dari ekokardiografi bisa didapatkan informasi mengenai ukuran dari katup mitral, ukuran atirum kiri, ada tidaknya thrombus pada ventrikel kiri dan ukuran dari jantung kanan. Pemeriksaan doppler pada ekokardiografi digunakan untuk mengetahui tingkat keparahan dari stenosis, mengetahui ada tidak nya lesi pada katup lain dan derajat hipertensi pulmonal. Jika hasil ekokardiografi tidak relevan dengan gejala klinis maka dapat dilakukan kateterisasi jantung. ${ }^{1}$

\section{Penatalaksanaan}

Stenosis mitral merupakan kelainan mekanis, oleh karena itu obat-obatan hanya bersifat suportif atau simtomatis terhadap gangguan fungsional jantung, atau pencegahan terhadap infeksi. Beberapa obat-obatan seperti antibiotik golongan penisilin, eritromisin, sefalosporin sering digunakan untuk demam reumatik atau pencegahan endokarditis. Obat-obatan inotropik negative seperti $\beta$-blocker atau $\mathrm{Ca}$ blocker, dapat memberi manfaat pada pasien dengan irama sinus yang memberi keluhan pada saat frekuensi jantung meningkat seperti pada latihan.

Fibrilasi atrium pada stenosis mitral muncul akibat gangguan hemodinamik yang bermakna akibat hilangnya kontribusi atrium terhadap pengisian ventrikel serta frekuensi ventrikel yang cepat. Pada keadaan ini pemakaian digitalis merupakan indikasi, dapat dikombinasikan dengan penyekat beta atau antagonis kalsium. Antikoagulan warfarin sebaiknya digunakan pada stenosis mitral dengan fibrilasi atrium atau irama sinus dengan kecenderungan pembentukan trombus untuk mencegah fenomena tromboemboli. ${ }^{6,14,15}$

Intervensi bedah, reparasi atau ganti katup (komisurotomi) pertama kali diajukan oleh Brunton pada tahun 1902 dan berhasil pertama kali pada tahun 1920. Akhir-akhir ini komisurotomi bedah dilakukan secara terbuka karena adanya mesin jantung-paru. Dengan cara ini katup terlihat jelas antara pemisahan komisura, atau korda, otot papilaris, serta pembersihan kalsifikasi dapat dilakukan dengan lebih baik. Juga dapat ditentukan tindakan yang akan diambil apakah itu reparasi atau penggantian katup mitral dengan prostesis. ${ }^{6,10}$

Indikasi dilakukannya operasi antara lain: (1) stenosis sedang sampai berat, dilihat dari beratnya stenosis $\left(<1,5 \mathrm{~cm}^{2}\right)$ dan keluhan; (2) stenosis mitral dengan hipertensi pulmonal; dan (3) stenosis mitral dengan resiko tinggi terhadap timbulnya emboli, seperti usia tua dengan fibrilasi atrium, pernah mengalami emboli sistemik, dan pembesaran yang nyata dari appendage atrium kiri. Sedangkan pada wanita hamil yang memiliki penyakit jantung harus diklasifikasikan terlebih dahulu dan penatalaksanaannya akan sesuai dengan klasifikasi tersebut.

Jenis operasi yang dapat dilakukan pada mitral stenosis, yaitu: (1) closed mitral commissurotomy, yaitu pada pasien tanpa komplikasi; (2) open commissurotomy (open mitral valvotomy), dipilih apabila ingin dilihat dengan jelas keadaan katup mitral dan apabila diduga adanya trombus di dalam atrium; (3) mitral valve replacement, biasa dilakukan apabila stenosis mitral disertai regurgitasi dan kalsifikasi katup mitral yang jelas. ${ }^{10,14,15}$

\section{Prognosis}

Apabila timbul atrial fibrilasi prognosisnya kurang baik (25\% angka harapan hidup 10 tahun) dibandingkan pada kelompok irama sinus (46\% angka harapan hidup 10 tahun). Hal ini 
dikarenakan angka resiko terjadinya emboli arterial secara bermakna meningkat pada atrium fibrilasi. ${ }^{1}$ Pada penelitian yang dilakukan oleh Rowe dkk pada tahun 1925 terhadap 250 penderita mitral stenosis, setelah sepuluh tahun 39\% penderita meninggal dunia, $22 \%$ menjadi semakin sesak dan $16 \%$ memiliki setidaknya satu manifestasi komplikasi tromboemboli. Setelah 20 tahun kemudian, 7\% meninggal dunia, $8 \%$ penderita menjadi semakin sesak dan $26 \%$ memiliki setidaknya satu manifestasi tromboemboli. ${ }^{12}$

Secara keseluruhan 10-years survival rate dari penderita stenosis mitral tanpa pengobatan lanjut hanya sekitar $50-60 \%$, tergantung dari keluhan yang timbul saat itu. Tanpa tindakan pembedahan, 20years survival rate hanya sekitar $85 \%$. Penyebab kematian pada penderita yang tidak mendapat pengobatan, yaitu: ${ }^{6,10}(1)$ gagal jantung (60-70\%); (2) emboli sistemik (20-30\%); (3) emboli paru (10\%); dan (4) infeksi (1-5\%). ${ }^{17,18}$

Pada penderita stenosis mitral, kehamilan umumnya masih dapat ditoleransi. Kadang-kadang dapat disertai gagal jantung kongestif atau aritmia semasa kehamilan dan harus diterapi. Jika tidak disertai hipertensi pulmonal, tidak akan mempengaruhi mortalitas maternal. Mortalitas janin dapat mencapai 20\% jika ibu yang lesinya tidak dikoreksi. Kemungkinan janin mempunyai penyakit jantung bawaan sebesar 5-10\%, dan nilai ini tidak berubah walaupun telah dilakukan tindakan bedah koreksi sebelumnya. ${ }^{19}$

\section{KASUS}

Pasien perempuan 24 tahun dengan primigravida hamil 32-34 minggu dengan mitral stenosis berat, gagal jantung stadium $\mathrm{C}$ kelas fungsional III. Dari anamnesa didapatkan bahwa pasien mengeluh sesak sejak kehamilan usia 4 bulan. Sesak bertambah jika beraktivitas dan berkurang saat istirahat. Dari pemeriksaan didapatkan airway patent, nafas spontan adekuat, jantung dan paru tidak ada kelainan. Pemeriksaan lain dalam batas normal.

Hasil laboraturium didapatkan anemia (hemoglobin 10,5 gr/dL), hipoalbumin $(3,31 \mathrm{gr} / \mathrm{dL})$. Analisis gas darah $\mathrm{pH} 7.52$, $\mathrm{PaCO}_{2} 36 \mathrm{mmHg}, \mathrm{PaO}_{2} 129.0 \mathrm{mmHg}$, $\mathrm{HCO}_{3} 29.5 \mathrm{mEq} / \mathrm{L}$, BE 5,5, saturasi $\mathrm{O}_{2}$ 98.9\% dengan nasal kanul $3 \mathrm{~L} /$ menit. Didapatkan kardiomegali dengan Cardiothoracic Ratio $\quad 62 \%$. Ekokardiografi didapatkan stenosis mitral berat, regurgitasi mitral ringan, regurgitasi trikuspid berat, regurgitasi pulmonal moderat, fungsi sistolik kedua ventrikel baik (EF 62\%), gangguan fungsi diastolik, dilatasi atrium kiri, ventrikel kanan, dan atrium kanan, hipertensi pulmonal (PASP $65 \mathrm{mmHg}$ ).

\section{PEMBAHASAN}

Teknik anestesi regional dipilih dengan pertimbangan kondisi klinis masih baik. Pasien masih bisa tidur terlentang dengan saturasi oksigen menggunakan udara ruangan 96-97\%. Prinsip utama pembiusan pada pasien dengan mitral stenosis adalah dengan tujuan menghindari takikardia, menjaga kondisi sinus rhytm dan secara agresif mengatasi kejadian baru dari atrial fibrilasi baik farmakologis maupun dengan kardioversi terutama pada pasien dengan hemodinamik yang tidak baik, menghindari penurunan SVR yang akan menimbulkan kompensasi berupa peningkatan denyut jantung sehingga memperberat kerja jantung, menghindari hipovolemi dan kelebihan cairan menghindari faktor yang dapat meningkatkan tekanan arteri pulmonal seperti hipoksia dan hiperkarbia maupun nyeri. $^{17}$ 
Peningkatan denyut jantung (sinus takikardia), fibrilasi atrial dapat memperpendek periode pengisian diastolik yang akan mengganggu pengosongan atrium kiri sehingga meningkatkan perbedaan tekanan yang melewati katup mitral dan berakibat peningkatan tekanan di atrium kiri. Selain itu, fibrilasi atrial juga dapat mengurangi pengisian ventrikel kiri sehingga berpengaruh pada cardiac output. ${ }^{14,19}$

Penggunaan monitor invasif seperti Central Venous Catheter (CVC) dan Arterial Blood Pressure (ABP) tergantung pada kompleksitas prosedur dan kemungkinan gangguan yang besar pada fisiologis seperti kehamilan. Digunakan $5 \mathrm{mg}$ bupivacaine heavy 0,5\% dengan adjuvant fentanyl $50 \mathrm{mcg}$ dengan total volume $2 \mathrm{ml}$ dengan menggunakan needle 27-G yang diinsersikan melalui tuffier's line dan kemudian pasien diposisikan supine segera setelah injeksi, tanpa head up maupun head down. Kami dapatkan bahwa skor Bromage 2 tercapai dalam dalam 59-63 detik, Bromage 1 dalam 8999 detik dan Bromage 0 dicapai dalam 130-170 detik setelah insersi. Sedangkan ketinggian blok T6 tercapai dalam 4 menit. Waktu insisi antara 5 menit hingga 10 menit.

Hemodinamik setelah injeksi bupivakain dan fentanyl intratekal stabil. Fluktuasi hemodinamik sangat minimal dan sesuai dengan hemodinamik awal dari pasien. Sebelum dilakukan spinal pasien ini dipasang CVC dan ABP. Saturasi pasien dengan udara ruangan sebelum spinal 94-95\% dan selama operasi berlangsung pasien menggunakan nasal kanul 3 L/menit dan saturasi 98-100\%. Kenaikan nadi setelah bayi lahir disebabkan oleh pemberian oksitosin. Selama operasi dan pascaoperasi tidak didapatkan keluhan sesak nafas, mual, muntah dan pusing serta tidak terjadi hipotensi sehingga tidak digunakan obat-obatan untuk menaikkan tekanan darah. Skor APGAR bayi 6-8. Pasien diobservasi di ICU dengan hemodinamik stabil sehingga pada hari ke- 3 setelah operasi pasien dapat kembali ke ruangan biasa.

Dosis rendah bupivakain hiperbarik dikombinasikan dengan fentanyl menghasilkan blok yang adekuat dengan efek samping sistemik yang minimal berupa penurunan tahanan sistemik vaskular dan mencegah timbulnya hipotensi pada anestesi spinal. Dikarenakan aliran darah uterus tidak bersifat autoregulasi, maka perfusi uteroplasental berhubungan secara langsung dengan tekanan darah ibu. Karena itu penurunan tekanan darah ibu masih dapat ditoleransi oleh ibu tetapi tidak oleh janin. Salah satu strategi untuk mempertahankan hemodinamik yang stabil selama dilakukan spinal anestesi pada operasi sesar adalah dengan menggunakan bupivakain dosis rendah yang dikombinasikan dengan ajuvan opioid. Pada laporan kasus ini juga kami tidak menemukan adanya episode hipotensi dan desaturasi.

Anestesi lokal intratekal bekerja dengan menghambat voltage-gated sodium channels pada medula spinalis yang akan mempengaruhi impuls motorik dan sensorik dari serabut aferen dan eferen. Tingkat blok sensorik dan motorik ini tergantung pada teknik, agen dan dosis yang diberikan. Opioid yang diberikan ke ruang intratekal secara selektif akan menghasilkan efek analgesia dengan melalui interaksi dengan reseptor opioid di cornu dorsalis medula spinalis dan dengan demikian dapat meminimalkan dosis serta efek supraspinal dari lokal anestesi seperti hipotensi, depresi nafas, sedasi dan mual muntah. Lokasi utama 
dari reseptor opioid adalah pada substantia grisea dari substansia gelatinosa. Hal inilah yang menjadi dasar anatomi terjadinya selektif analgesia setelah opioid intratekal diberikan. ${ }^{7,9,18}$

Opioid intratekal secara selektif akan memblok transmisi stimulus dari serabut saraf $\mathrm{A}, \delta$ dan $\mathrm{C}$ afferent nociceptive dengan membentuk ikatan pada reseptor opioid di prasinaps dan pascasinaps. Pada pascasinaps, opioid akan meningkatkan konduksi ion kalium, meningkatkan hiperosmolaritas neuronneuron asendens tanpa membangkitkan efek somatosensorik maupun motorik. Efek prasinaps antara lain pelepasan adenosin spinal yang berperan penting sebagai mediator spesifik analgetik. ${ }^{9,11}$

Fentanyl bekerja secara sinergis dengan bupivakain dalam menurunkan ambang nyeri tanpa meningkatkan blokade simpatis dan motorik. Telah banyak penelitian yang membuktikan efektifitas penggunaan opioid pada anestesi spinal terutama pada operasi sesar. Penelitianpenelitian sebelumnya membuktikan bahwa opioid lipofilik contohnya fentanyl dapat mempercepat awitan dan memperpanjang durasi blok bupivakain, serta memperpanjang durasi analgesia pascaoperasi. Kombinasi keduanya memiliki kecepatan awitan 5 menit secara intratekal dan 10 menit melalui epidural dan secara relatif memiliki durasi aksi yang lebih pendek dikarenakan oleh adanya redistribusi (24 jam intratekal dan epidural). Tidak didapatkan adanya metabolit aktif dan memiliki sifat 800 kali lebih larut dalam lemak dibandingkan morfin. Dan karena kelarutan yang sangat tinggi dalam lemak sehingga secara cepat akan berikatan dengan reseptor opioid di cornu dorsalis medula spinalis, dan awitan yang cepat ini sangat menguntungkan baik sebagai analgesia pada persalinan normal maupun pada kasus operasi sesar emergensi. ${ }^{12}$

Dosis rendah bupivakain telah dipakai pada operasi sesar (contohnya bupivakain $5 \mathrm{mg}$ dengan fentanyl 25 mcg). Prinsip utamanya adalah untuk mengurangi hipotensi. Angka kejadian hipotensi sekitar $31 \%$ pada pasienpasien yang diberi bupivakain $5 \mathrm{mg}$ yang dikombinasikan dengan fentanyl 25 mcg, jika dibandingkan dengan pasien yang hanya mendapatkan bupivakain 10 mg tanpa opioid dimana angka kejadian hipotensi yang mencapai 94\%. Larutan spinal anestesi hiperbarik juga telah disiapkan dengan menggabungkan antara larutan anestesi lokal dengan dekstrosa (glukosa). Densitas lokal anestesi berbanding lurus dengan konsentrasi dekstrosa. Namun pada wanita tidak hamil, konsentrasi dekstrosa yang lebih rendah telah terbukti memiliki efek concentrationdependent dalam mendistribusikan bupivakain $0,5 \%$ secara cephalad. Perbedaan densitas antara cairan serebrospinal dan larutan anestesi lokal hiperbarik dekstrosa $0,8 \%$ menjadi lebih besar pada ibu hamil jika dibandingkan dengan wanita yang tidak hamil, yang memungkinkan terjadinya distribusi yang lebih cephalad..$^{11,15}$

Pemilihan teknik anestesi yang digunakan harus mempertimbangkan status hemodinamik parturien saat datang, tipe dari penyakit jantungnya, penggunaan obat-obatan sebelumnya, serta jenis operasinya elektif atau emergensi. Regional anestesi merupakan kontraindikasi pada pasien dengan stenosis kasus yang berat dengan hemodinamik tidak stabil, hipoksia berat dan penggunaan antikoagulan. Pasien dengan NYHA kelas III dan IV sebaiknya tidak menggunakan anestesi 
spinal mengingat kemungkinan penurunan hemodinamiknya. Pada pasien dengan hemodinamik stabil, teknik anestesi epidural murni maupun kombinasi epidural-spinal dosis rendah menurut beberapa literatur lebih direkomendasikan daripada anestesi umum. Anestesi umum diketahui mendepresi kontraktilitas jantung, meningkatkan resistensi pembuluh darah pulmoner melalui ventilasi tekanan positif. Tindakan laringoskopi dan intubasi serta kemungkinan aspirasi juga dapat menyebabkan perubahan hemodinamik pada pasien yang menjalani anestesi umum. ${ }^{6,12,13}$ Tatalaksana perioperatif harus melibatkan multidisiplin (melibatkan bagian jantung, obsgin, dan paru) untuk menangani komplikasi yang mungkin dapat timbul.

Sampai saat ini anestesi spinal pada pasien dengan stenosis mitral masih merupakan kontraindikasi. Pada pasien ini dilakukan anestesi spinal dengan memenuhi hal-hal yang harus diperhatikan pada anestesi dengan mitral stenosis yaitu menghindari takikardia, menjaga kondisi sinus rhytm dan secara agresif mengatasi kejadian baru dari atrial fibrilasi, menghindari penurunan SVR, menghindari hipovolemi dan kelebihan cairan serta menghindari faktor yang dapat meningkatkan tekanan arteri pulmonal. Penelitian sebelumnya menyimpulkan bahwa low dose anestesi spinal tidak menyebabkan perubahan hemodinamik dan fentanyl sebagai adjuvant mempunyai efek memperpanjang analgesia dan blok motorik yang adekuat sehingga pada pasien ini kami lakukan pembiusan dengan low dose anestesi spinal dan tidak ditemukan adanya kejadian hipotensi maupun perubahan hemodinamik yang lain. ${ }^{13,20-25}$

\section{KESIMPULAN}

Prinsip utama pembiusan pada pasien dengan mitral stenosis adalah menghindari takikardia, menjaga kondisi sinus rhytm dan secara agresif mengatasi kejadian baru dari atrial fibrilasi, menghindari penurunan SVR, menghindari hipovolemi dan kelebihan cairan serta menghindari faktor yang dapat meningkatkan tekanan arteri pulmonal. Pada pasien ini anestesi spinal dengan low dose dapat digunakan sebagai alternatif pembiusan pada pasien dengan mitral stenosis karena hemodinamik yang stabil dibandingkan dengan spinal konvensional.

\section{DAFTAR PUSTAKA}

1. Boom, CE. Panduan Klinis Perioperatif Kardiovaskular Anestesia. Universitas Padjadjaran Bandung: Aksara Bermakna 2013

2. Carapentis JR. Rheumatic heart disease In Asia. Circulation. 2008;118(25):2748-53

3. Thamilarasan $\mathrm{M}$, Civello $\mathrm{K}$, Griffin BP. Mitral Valve Disease. Manual of cardiovascular medicine second edition. Philadelpia: Lippincot Williams and Wilkins; 2004. p.314

4. Gartner M, Youngblood C. Case report in anestesiology: essential pulmonary hypertension in a primigravida. Anestesiol Open J. 2016; 1(1): 24-27. doi: 10.17140/AOJ-1-106

5. Grindheim $\mathrm{G}$, Estensen $\mathrm{ME}$, Langesaeter E, Rosseland LA, Toska K. Changes in blood pressure during healthy pregnancy: A longitudinal cohort study.

J Hypertens.2012;30(2):342-50. doi:

10.1097/HJH.0b013e32834f0b1c

6. Isngadi, Rafidya IS. 2017. Manajemen Anestesi Pada 
Kehamilan Dengan Penyakit Jantung. Departemen Anestesiologi dan Terapi Intensif FKUB RSUD Dr. Saiful Anwar, Malang. 2017: 78

7. Butterwort, John F, Mackey, David C, Wasnic, John D. Morgan and Mikhail's Clinical Anestesiogy. USA: The McGraw Hill Companies; 2013: p 827-828

8. Chestnut DH, et all. Chestnut's Obstetric Anestesia 5th edition. Elsevier: Philadelphia; 2014: p 985

9. Pardo CM, Miller RD. Basic of Anestesia 7th edition, Elsevier, Philadelphia, 2018: p.554-556

10. Hensley FA, Martin DE, Gravlee GP. A Practical Approach to Cardiac Anestesia 5th Edition. Philadelphia: Lippincott William and Wilkins; 2013.p.337-341

11. Hines RL, Marschall KE. Stoelting's Anestesia and Coexisting Disease. Elsevier: Philadelphia; 2018: p 110-113

12. Kannan M, Vijayanand G. Mitral Stenosis and Pregnancy: Current Concepts in Anesthetic Practice. Indian Journal of Anethesia. 2010: p 439-444

13. Willson, Paul et all. Matrenal parameter in lower segment Cesarian section: comparative study of the effect of low dose spinal Anestesia. Kerala, India: International Journal of Reproduction, Contraception, Obestetric Gynecology; 2016

14. Braunwald E, Bonow RO. Braunwald's heart disease: a textbook cardiovascular medicine. 9th edition. Philadelphia: Saunders; 2012.

15. Sarah T, Athena P. Mitral valve disease in pregnancy: outcomes and management. Obstetric Medicine 2009; 2: $6-10$. DOI: 10.1258/om.2008.080002
16. Abhijit P, Sucharita D. Valvular heart disease and anaesthesia. Indian Journal of Anaesthesia. 2017;61 (9): 721-727

17. Ruys TP, Roos-Hesselink JW, Hall R. Heart failure in pregnant women with cardiac disease: data from the ROPAC. Heart 2014; 100: 231

18. Goldszmidt E, Macarthur A, Silversides C, et al. Anesthetic management of a consecutive cohort of women with heart disease for labor and delivery. Int $\mathrm{J}$ Obstet Anesth. 2010; 19:266.

19. Nishimura RA, Otto CM, Bonow RO, et al. 2014 AHA/ACC guideline for the management of patients with valvular heart disease: a report of the American College of Cardiology/American Heart Association Task Force on Practice Guidelines. J Am Coll Cardiol. 2014; 63:e57.

20. Regitz-Zagrosek V, RoosHesselink JW, Bauersachs J, et al. 2018 ESC Guidelines for the management of cardiovascular diseases during pregnancy. Eur Heart J. 2018; 39:3165.

21. Creanga AA, Syverson C, Seed K, Callaghan WM. PregnancyRelated Mortality in the United States, 2011-2013. Obstet Gynecol. 2017; 130:366.

22. Hamlyn EL, Douglass CA, Plaat F, et al. Low-dose sequential combined spinal-epidural: an anaesthetic technique for caesarean section in patients with significant cardiac disease. Int $\mathrm{J}$ Obstet Anesth. 2005; 14:355.

23. Bonnin M, Mercier FJ, Sitbon O, et al. Severe pulmonary hypertension during pregnancy: mode of delivery and anesthetic management of 15 consecutive cases. Anestesiology. 2005; 
102:1133.

24. Hameed A, Karaalp IS, Tummala PP, et al. The effect of valvular heart disease on maternal and fetal outcome of pregnancy. J Am Coll Cardiol. 2001; 37:893.

25. Leśniak-Sobelga A, Tracz W,
KostKiewicz M, et al. Clinical and echocardiographic assessment of pregnant women with valvular heart diseases--maternal and fetal outcome. Int J Cardiol. 2004; 94:15. 